\title{
Gangrenous Mastitis in a Pseudo Pregnant Bitch - A Case Report
}

\author{
Alok Singh*, Sujeet Kumar Chaudhary and Ankur Upadhyay \\ Department of Veterinary Medicine, COVSc. \& A.H. \\ DUVASU, Mathura- 281001(U.P.), India \\ *Corresponding author
}

\section{A B S T R A C T}

\section{Keywords \\ Gangrenous mastitis, Pseudo pregnant bitch, Staphylococcus aureus \\ Article Info \\ Accepted: \\ 06 June 2018 \\ Available Online: \\ 10 July 2018}

\section{Introduction}

Canine mastitis is considered as a reproductive disease of an unusual type (Wiebe and Howard, 2009). Manifestation of mastitis is influenced either by an ascending infection of the mammary gland due to bacteria, any traumatic injury to the mammary tissues or unhygienic surroundings (Jutkowitz, 2005). Among various isolates of bacteria Escherichia coli, Staphylococci, and Streptococci are considered as most common etiological agents of mastitis (Ververidis et al., 2007). Its severity ranges from acute one to chronic one (Traas et al., 2007). Most common clinical signs associated with mastitis are firm, painful, swollen, mammary gland which may also change in colour and appearance beside this there may or may not abnormal secretion from the affected mammary gland. There may be development of gangrene in severely affected glands. Signalment, clinical signs, and cytological evaluation of milk are considered as basis of the diagnosis. Therapeutic management plan includes the use of antibiotics which are susceptible to the etiological agent and execute their action at mammary tissue bed, beside this they also concentrate in milk without showing any harmful effect to suckling young ones (Wiebe and Howard, 2009). In such conditions where glands 
become necrotic, neonates should be removed, and the affected gland should be surgically managed (Traas et al., 2007 and Hopper, 2009).

\section{History}

An intact German shepherd bitch having age of 3 years and also pseudo pregnant was presented at TVCC Mathura with the chief complaint of anorexic, dull, depressed, hot hyperaemic red patches in the ventral aspect of abdomen around the area adjoining the teats, edematous quarters, along with cool and necrosed teats (Fig. 1).

\section{Clinical observation}

On clinical examination we found unremarkable vital parameters along with its general behaviour. On performing the routine haematology on day zero we found increase in total Leukocyte count, decrease in mean corpuscular volume, and decrease in platelets number. On performing culture test of the material, fluid taken from the necrosed teat we found Staphylococcus aureus as a chief causative agent (Fig. 2 and 3). Based on history and clinical examination findings gangrenous mastitis was diagnosed in that case. After diagnosis suitable treatment is recommended to the patient. On follow up after 5 days of post treatment we found that the affected bitch shows clinical recovery in the form of reduction in the above said clinical signs. We also performed the routine haematology and found that increased total leucocyte count comes to the normal range value along with normal range mean corpuscular volume, and platelets number.

\section{Treatment and Discussion}

The treatment of the affected bitch was initiated by prescribing parentral administration of Injection Intacef tazo pet $562.5 \mathrm{mg}$ (Ceftriaxone $500 \mathrm{mg}$, Tazobactum $62.5 \mathrm{mg}$ ) SID, intravenously for 5days and to reduce the severity of the inflammation single dose of Injection Flunixin meglumine $5 \%$ w/v) @ $1.1 \mathrm{mg} / \mathrm{kg}$ body weight, intravenously was advised. Beside this Tablet Pantop-D 40 mg (Pantoprazole $20 \mathrm{mg}$ and Domperidone 10 mg)@ 1 tab, BID, for 5 days should recommended. The owner should also advised to apply topically Ointment Prestivet (Aceclofenac 1.50\%, Linseed Oil 3\%, Methyl Salicylate 10\%, Menthol 5\%,Capsaicin $0.01 \%$ ) over the inflamed area BID for 5 days. An eventful recovery was observed after $5^{\text {th }}$ day of treatment.

As we know that the mastitis in canine is an infrequent condition (Schlafer and Miller, 2007). Normally the condition arises due to the bacterial infection of the mammary gland and the mammary tissue (Ververidis et al., 2007). Staphylococcus aureus is considered as main etiological agent in this present case. The nature of the clinical mastitis in bitches either may be localised or diffuse where single or multiple mammary gland may be infected (Barsanti, 2006). Therapeutic management of mastitis must be initiated immediately by the use of antibiotics whose spectra of action is wide and effective agents the common causative isolates of mastitis (Wiebe and Howard, 2009). For obtaining best result we follow the same principal of treatment in the present case.

Fig.1 Shows Necrosed teats and lesion around the teats

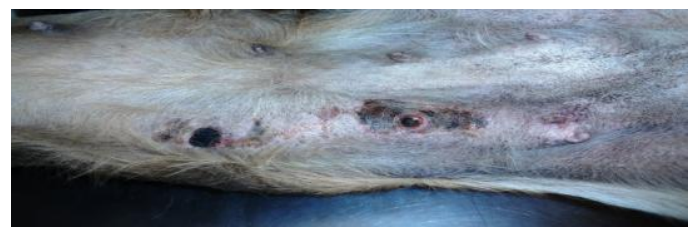


Figure.2 Staphylococcus aureus colonies appear black and shiny in selective Baired Parker agar media

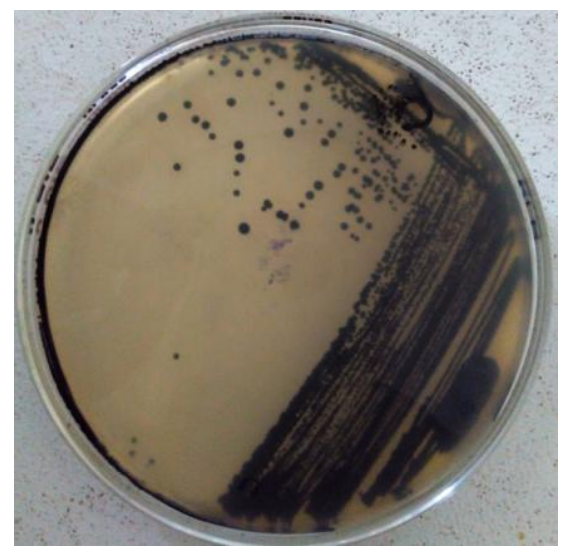

\section{References}

Barsanti, J.A. 2006. Genitourinary infections. In: Greene, CE. Infectious diseases of the dog and cat. $3^{\text {rd }}$ Ed., St Louis: Saunders Elsevier, 91: 935-61.

Hopper K. 2003. Pyometra, mastitis and uterine prolapse. International Veterinary Emergency and Critical Care Symposium; New Orleans, Louisiana, USA. August 9-13.

Jutkowitz LA. 2005. Reproductive emergencies. Vet Clin Small Anim. 35:397-420.

Schlafer, D.H., Miller, R.B. 2007. Female genital system. In: Jubb KVF., Kennedy PC., Palmer's NC.
Figure.3 Oxygen bubbles shows Catalase test positive a characteristic of gram positive Cocci

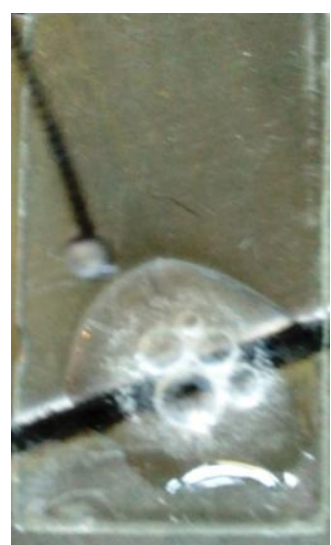

Pathology of domestic animals. 5th Ed., Philadelphia: Saunders Elsevier 4: 429-64.

Traas AM, O’Connor C. 2009. Postpartum emergencies. International Veterinary Emergency and Critical Care Symposium.

Ververidis HN, Mavrogianni VS, Fragkou IA, et al., 2007. Experimental staphylococcal mastitis in bitches: Clinical, bacteriological, cytological, haematological and pathological features. Vet Microbiol. 124:95-106.

Wiebe VJ, Howard JP. 2009. Pharmacologic advances in canine and feline reproduction. Top Companion Anim Med. 24:71-99.

\section{How to cite this article:}

Alok Singh, Sujeet Kumar Chaudhary and Ankur Upadhyay. 2018. Gangrenous Mastitis in a Pseudo Pregnant Bitch - A Case Report. Int.J.Curr.Microbiol.App.Sci. 7(07): 806-808. doi: https://doi.org/10.20546/ijcmas.2018.707.098 